\title{
Malaria outbreaks in a non-endemic area of Brazil, 2005
}

\author{
Surtos de malária em área não endêmica do Brasil, 2005
}

\author{
Jean Ezequiel Limongi ${ }^{1}$, Kátia Maria Chaves $^{2}$ Márcia Beatriz Cardoso de Paula $^{1}$, \\ Fabíola Corrêa da Costa ${ }^{3}$, Alcides de Assis e Silva ${ }^{1}$, Íris de Sousa Lopes ${ }^{1}$, \\ Adalberto de Albuquerque Pajuaba Neto ${ }^{1}$, José Maria Sales ${ }^{4}$ Fernando Rodrigues $^{2}$, \\ Maria Angélica Montes Resende ${ }^{2}$ and Marcelo Simão Ferreira ${ }^{5}$
}

\begin{abstract}
In March 2005, a resident of the municipality of Monte Alegre de Minas, State of Minas Gerais, without any history of traveling to endemic areas for malaria, was diagnosed with Plasmodium vivax infection and local mosquito-borne transmission was suspected. The epidemiological investigation identified another 10 cases with local transmission and all of them were related to the imported malaria case that was detected in this region. The potential exposure site was the banks of the river Tejuco, an area frequented by mineral prospectors. Some of these prospectors were known to have come from states with malaria transmission. In the autochthonous cases, Plasmodium vivax and Plasmodium falciparum were diagnosed. Entomological investigation identified Anopheles (Nyssorbynchus) darlingi, Anopheles (Nyssorhynchus) albitarsis, Anopheles (Nyssorbynchus) triannulatus and Anopheles (Nyssorhynchus) parvus. After the first outbreak, another three autochthonous cases were notified in municipality of Monte Alegre de Minas, in the same year. The occurrence of these outbreaks highlights the importance of surveillance systems in areas that are nonendemic for malaria.
\end{abstract}

Key-words: Malaria. Plasmodium falciparum. Plasmodium vivax. Outbreaks. State of Minas Gerais.

\section{RESUMO}

Em março de 2005, um morador do município de Monte Alegre de Minas, Estado de Minas Gerais, sem histórico de viagem para área endêmica de malária foi diagnosticado com infecção por Plasmodium vivax e a transmissão vetorial no local foi suspeitada. A investigação epidemiológica identificou outros 10 casos com transmissão local e todos relacionados ao caso de malária importada detectado na região. A área de potencial exposição foi às margens do rio Tejuco, local freqüentado por garimpeiros, muitos sabidamente, oriundos de estados com transmissão de malária. Nos casos autóctones, Plasmodium vivax e Plasmodium falciparum foram diagnosticados. A investigação entomológica identificou Anopheles (Nyssorhynchus) darlingi, Anopheles (Nyssorhynchus) albitarsis, Anopheles (Nyssorhynchus) triannulatus eAnopheles (Nyssorhynchus) parvus. Após o primeiro surto, outros três casos autóctones foram notificados no município de Monte Alegre de Minas no mesmo ano. A ocorrência desses surtos alerta sobre a importância de sistemas de vigilância em áreas não endêmicas para a malária.

Palavras-chaves: Malária. Plasmodium falciparum. Plasmodium vivax. Surtos. Estado de Minas Gerais.

In the State of Minas Gerais, which is outside of the Amazon region, most of the malaria cases that are recorded are imported from states within the endemic area of the Amazon region. Between 1980 and 2004, 11,272 confirmed cases of malaria were registered, of which 10,766 were imported (annual average of 431 cases) from endemic areas and 506 were autochthonous (annual average of 20 cases) ${ }^{2} 910$. Of these autochthonous cases, 481 occurred in typically rural areas of the State (KM Chaves: unpublished data).

Endemic malaria has been eradicated from the State of Minas Gerais since the end of the $1970 \mathrm{~s}^{7}$. However, sporadic transmission of the malaria occurs in the state, caused by mosquitoes that are locally infected. Like other areas of Brazil, this State has the potential for malaria to occur: receptivity, through the presence of environmental conditions that are favorable towards mosquitoes of the genus Anopheles, with vector capacity; and vulnerability, through the constant presence of infected individuals coming from endemic areas, due to migratory flows between the State of Minas Gerais and such areas ${ }^{910} 13$.

In addition, the low familiarity among health professionals regarding diagnostic and therapeutic approaches, and the poor

\footnotetext{
1. Centro de Controle de Zoonoses de Uberlândia, Secretaria de Saúde de Uberlândia, Uberlândia, MG. 2. Secretaria de Estado de Saúde de Minas Gerais, Belo Horizonte, MG. 3. Instituto de Ciências Biomédicas, Universidade Federal de Uberlândia, Uberlândia, MG. 4. Laboratório Macro-Regional de Saúde Pública, Uberaba, MG. 5. Serviço de Moléstias Infecciosas, Hospital de Clínicas, Universidade Federal de Uberlândia, Uberlândia, MG.

Address to: Dr. Jean Ezequiel Limongi. Av. Alexandrino Alves Vieira 1423, Bairro Liberdade, 38401-240 Uberlândia, MG.

Tel: $55343213-1470$

e-mail: jeanlimongi@gmail.com

Recebido para publicação em: 30/01/2008

Aceito em: 02/06/2008
} 
knowledge of the disease among the general public are aggravating factors in patient management and malaria surveillance ${ }^{10}$.

This report describes investigations on 14 cases of Plasmodium spp infection that occurred in the municipalities of Monte Alegre de Minas and Prata, in the State of Minas Gerais, Brazil, in March, July and October 2005. These investigations were carried out by the State Health Department of Minas Gerais, together with the Municipal Health Departments of Monte Alegre de Minas, Prata and Uberlândia. The report discusses some aspects of malaria surveillance.

\section{MATERIAL AND METHODS}

Study area. The Tejuco river basin is located in the Triângulo Mineiro region, State of Minas Gerais, between the geographical coordinates of $18^{\circ} 40^{\prime}$ and $19^{\circ} 47^{\prime}$ south and $47^{\circ} 53^{\prime}$ and $50^{\circ} 13^{\prime}$ west. The basin covers about $27 \%$ of the Triângulo Mineiro, occupying a total of $14,249.05 \mathrm{~km}^{2}$. The Tejuco river forms the boundary between the municipalities of Prata and Monte Alegre de Minas and is frequently visited by itinerant prospectors coming from areas of Brazil that are endemic for malaria. The municipality of Monte Alegre de Minas is located in the mesoregion of the Triângulo Mineiro and Alto Paranaíba (18 $52^{\circ}$ ' 15" S, 48 $52^{\prime}$ $\left.51^{\prime} \mathrm{W}\right)$, at a median altitude of 730 meters. It occupies an area of $2,593.171 \mathrm{~km}^{2}$, and forms boundaries with the municipalities of Uberlândia, Tupacigurara, Prata, Ituiutaba, Canapólis and
Centralina. Its terrain is mainly formed by tablelands and residual plateaus, with an extensive hydrographic network. The natural vegetation is cerrado (savanna) with areas of tropical forest remainders. Most of the population works directly in the fields. The municipality of Prata is located in the middle of the Triângulo Mineiro. It occupies an area of 4,856.626 km² (19 $19^{\circ} 25^{\prime \prime} \mathrm{S}$, $\left.48^{\circ} 55^{\prime} 26^{\prime \prime} \mathrm{W}\right)$. The terrain consists of a sedimentary plateau and cerrado is the predominant vegetation, with tropical forest in the main river valleys (Figure 1).

Origin of outbreak. On March 4, 2005, a 41-year-old male patient was admitted to a hospital in Monte Alegre de Minas with symptoms of fever, chills and sweating. The diagnosis from blood tests performed at the reference laboratory in Uberlândia, Minas Gerais, was that the patient presented Plasmodium vivax. Epidemiological investigations confirmed that the patient did not have any history of traveling in areas where malaria transmission is endemic. In addition, it was confirmed that no risk factors such as blood transfusion, blood derivative transfusion, organ transplantation or previous malaria infections were present. It was suspected that there might be other autochthonous malaria cases, and an epidemiological investigation was started, directed by the State Health Department of Minas Gerais. On March 9, 2005, another case of infection by Plasmodium falciparum was confirmed, in a patient in hospital in the municipality of Uberlândia who had come from the municipality of Prata, thus strengthening the hypothesis of local transmission.

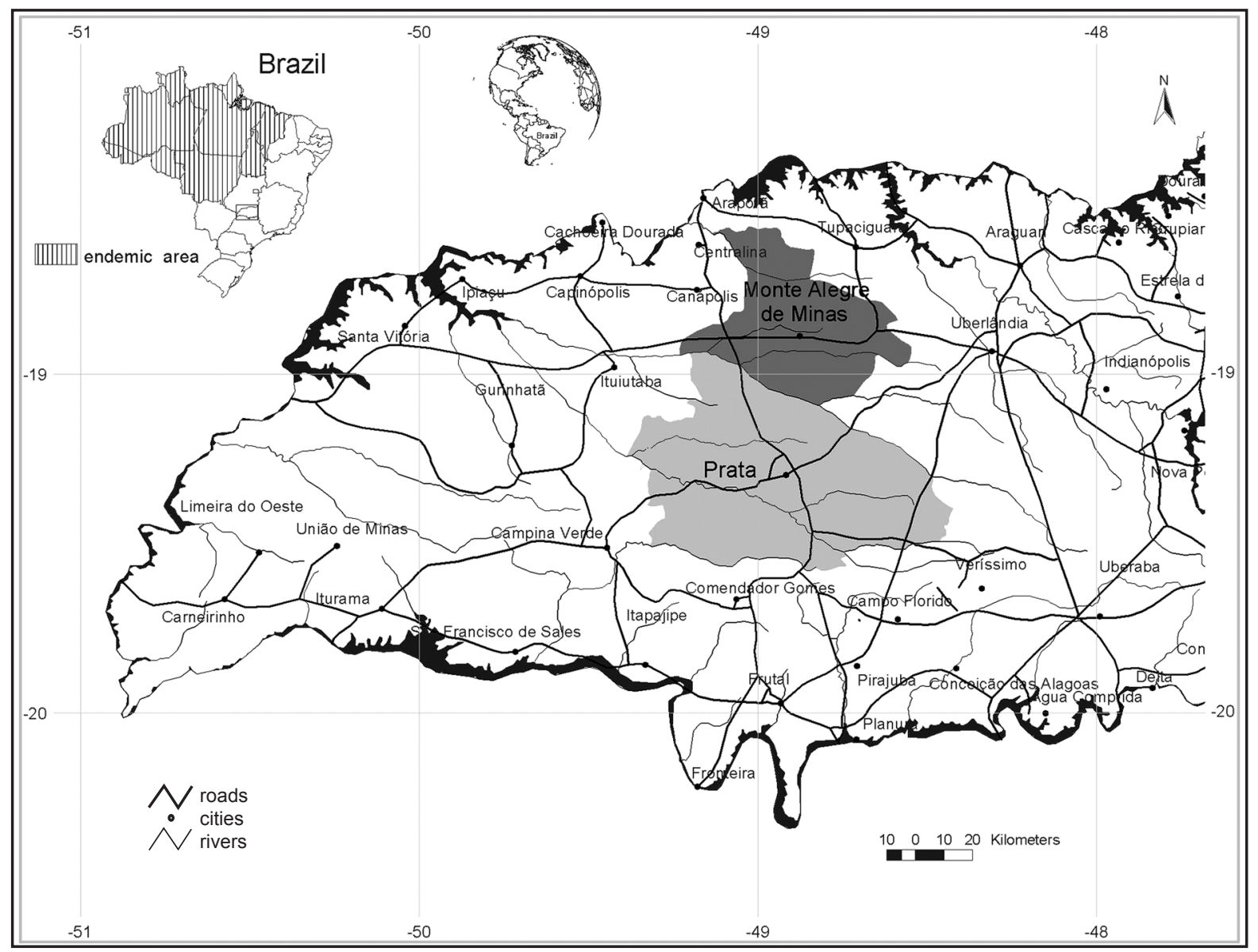

Figure 1 - Geographical location of the municipalities of Monte Alegre de Minas and Prata, Minas Gerais, highlighting the extensive road network of the region. 
Methodology for investigating the outbreak. The measures carried out were: i) epidemiological investigation of the index case and the primary source of infection, by means of an active search; ii) identification and geographical delineation of the focus of transmission by case mapping and epidemiological and entomological characterization; iii) logistical support for investigation, diagnosis and treatment, and promotion of technical improvements among the professionals of the health services in the municipalities involved.

Intervention measures. With the objective of ensuring the elimination of local transmission of malaria, the following actions were applied. 1) The health systems of the municipalities of Monte Alegre de Minas and Prata, along with adjacent municipalities, were alerted regarding the occurrence of autochthonous malaria transmission in the region and the need for careful investigation of febrile cases. 2) The Hemominas Foundation, the institution responsible for the hemotherapy and hematological system in the State of Minas Gerais, was alerted. 3) Geographical recognition of the localities with confirmed autochthonous cases, with the aim of ensuring an active search in 100\% of households. 4) Characterization of suspected cases: every individual who presented a clinical condition characterized by current or recent fever of unknown origin, along with chills, sweating, headache and/or other symptoms and signs of malaria; individuals coming from an endemic area; individuals living in outbreak areas; and individuals who had been present in places that were considered to be likely infection localities, were considered to be potentially infected. 5) Confirmed cases: individuals who presented parasites in the blood were identified have been identified through the blood test diagnosis. 6) Promotion of human resources and materials centralization, to detect and treat all positive cases of malaria. 7) Interviews with all suspected patients and their family members. With the aims of finding active cases, conducting entomological studies and applying insecticides, all homes within a five-kilometer radius from the home of the index case were considered to pertain to the focus area. In the event of detecting other possible transmission areas, new five-kilometer radiuses were delineated, totaling an area of $110 \mathrm{~km}^{2}$. The epidemiological follow-up on the outbreak was carried out over a two-month period, by means of active and passive searches every fifteen days. After evaluating the results obtained over this period, a bimonthly active search was carried out over a nine-month period starting from the beginning of the outbreak, to ensure that transmission was halted. 8) Collection of blood samples during the first cycle, from all symptomatic individuals and other family members living in the same home, even if asymptomatic. During the second cycle, blood samples were collected only from the patients presenting symptoms. 9) Therapeutics and follow-up to obtain proof that positive patients had been cured were implemented in accordance with the approved standards of the Brazilian Ministry of Health ${ }^{51}$. 10) Chemical treatment was administered inside all homes located within the investigation radius of the outbreak.

Entomological investigations. Entomological captures were carried out from March 14 to 24, 2005, inside and outside the homes, using either Shannon traps or suction capture devices, in four different areas situated near the focus region. The capture of adult anophelines was performed between the hours of 6:30 p.m. and 10:00p.m. The larvae were surveyed in water collected from different sites within the investigation radius of the outbreak, between 9:00a.m. and 10:00a.m. and between 4:00p.m. and 5:30p.m. The larvae were collected using ordinary ladles and were sent to the laboratory for development and subsequent identification of the adult. The insects collected were packed in tubes until they were morphologically identified. This was done at the Macroregion Public Health Laboratory in the municipality of Uberaba, Minas Gerais. The anophelines were identified using the key presented by Gorham et al ${ }^{6}$.

Parasitological diagnosis. The thick blood smear technique was used for the diagnosis, in accordance with the standards of the Brazilian Ministry of Health ${ }^{12}$. All the slides were examined within 24 hours of blood sample collection. The diagnoses were made at the Regional Malaria Reference Laboratory of the Uberlândia Zoonosis Control Center, which is located around $80 \mathrm{~km}$ from the focus.

Statistical analysis. The ANOVA and Fisher exact tests were used for comparisons between means and between proportions, respectively, using the Epi Info software package, version 3.3.2. The significance level was set at 5\%.

\section{RESULTS}

Origin and demarcation of the outbreaks. The active search for cases identified two prospectors who tested positive for Plasmodium vivax. They came from the State of Pará (diagnosed on March 9, 2005) and the State of Mato Grosso (diagnosed on March 13, 2005). The first of these two cases was probably the one that originated the outbreak, resulting in 11 autochthonous cases. The first autochthonous case was detected on March 4, 2005 and the last on March 18, 2005. These cases occurred in five rural localities on the boundary of the municipalities of Prata and Monte Alegre de Minas, along the Tejuco river. On July 29, 2005, a man living in the municipality of Monte Alegre de Minas, without any history of traveling to areas with active transmission, was diagnosed positive for Plasmodium vivax from laboratory tests. This occurred 26 days after going fishing along the Tejuco river. Later on, on October 6 and 13, 2005, two sisters were diagnosed with Plasmodium vivax infection in a locality outside of the investigation radius of the first outbreak, some $70 \mathrm{~km}$ from the Tejuco river focus. The source that introduced these three last cases remained undetected, in spite of information about the frequent presence of truck drivers in the region, coming from endemic areas. Most of the cases $(9 ; 64 \%)$ had had contact with the case that probably originated the malaria transmission in the region, along the banks of the Tejuco river, near the dredges and camps of the diamond prospectors who were present in the area at that time (Figure 2).

History of the cases. In Monte Alegre de Minas, eight cases were confirmed, all of Plasmodium vivax (Table 1). One of these cases, diagnosed on March 11, 2005, once again presented 


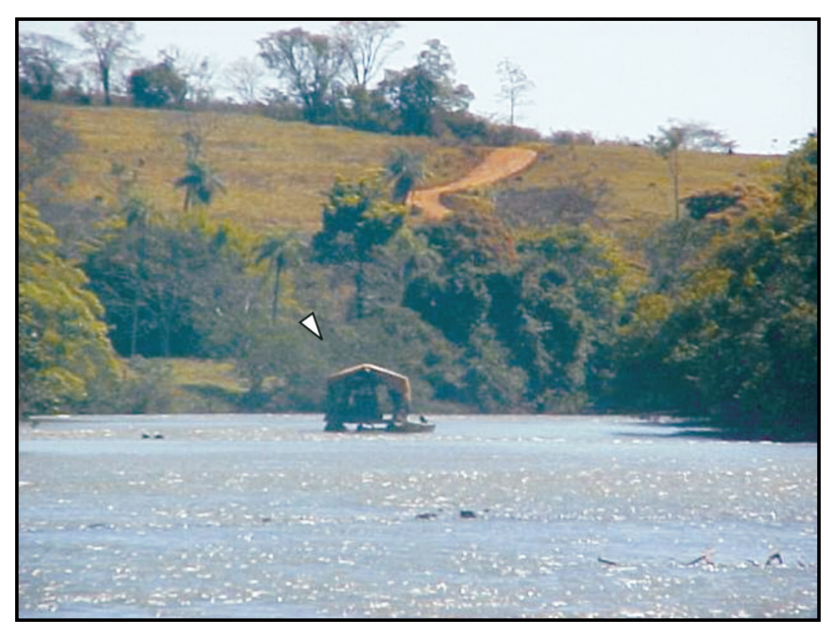

Figure 2 - Tejuco river, which forms the boundary between the municipalities of Monte Alegre de Minas and Prata, Minas Gerais, highlighting dredging activity for diamond prospecting (triangle).

a diagnosis of Plasmodium vivax on October 28, 2005. The epidemiological investigation of the case considered this to be a relapse. Another relapse occurred in an infant aged one year and seven months (Table 2). In the municipality of Prata, six cases were confirmed: three of Plasmodium vivax, two of Plasmodium falciparum and one of both of these species (Table 1). There were no recurrences among the cases recorded in this municipality. Among all the cases recorded in these two municipalities, most $(11 ; 79 \%)$ were males. However, analysis of the positive findings in relation to sex did not show any statistically significant difference $(\mathrm{p}=0.11)$. The mean age of the individuals who were positive

Table 1 - Sociodemographic and epidemiological characteristics of the autochthonous cases of Plasmodium spp in the municipalities of Monte Alegre de Minas and Prata, Minas Gerais, 2005.

\begin{tabular}{|c|c|c|}
\hline \multirow[t]{2}{*}{ Characteristics } & \multicolumn{2}{|c|}{ Frequency $(n=14)$} \\
\hline & $\mathrm{n}^{0}$ & $\%$ \\
\hline \multicolumn{3}{|l|}{ Sex } \\
\hline male & 11 & 79.0 \\
\hline female & 3 & 21.0 \\
\hline Age $(\text { mean } \pm \text { SD) })^{*}$ & \multicolumn{2}{|c|}{$(28.0 \pm 16.5)$} \\
\hline \multicolumn{3}{|l|}{ Occupation } \\
\hline farmer & 4 & 29.0 \\
\hline student & 2 & 14.0 \\
\hline mechanic & 1 & 7.0 \\
\hline attendant & 1 & 7.0 \\
\hline prospector & 1 & 7.0 \\
\hline nomad & 4 & 29.0 \\
\hline minor & 1 & 7.0 \\
\hline \multicolumn{3}{|l|}{ Origin } \\
\hline Monte Alegre de Minas & 8 & 60.0 \\
\hline Prata & 6 & 40.0 \\
\hline \multicolumn{3}{|c|}{ Contact with the transmission focus } \\
\hline occupational & 1 & 7.0 \\
\hline leisure & 3 & 21.5 \\
\hline outside the home & 7 & 50.0 \\
\hline no contact & 3 & 21.5 \\
\hline \multicolumn{3}{|l|}{ Hospitalization } \\
\hline yes & 10 & 71.0 \\
\hline no & 4 & 29.0 \\
\hline
\end{tabular}

SD: standard deviation for Plasmodium spp was not significantly different from the mean age of individuals who had negative parasite diagnosis $(\mathrm{p}=0.09)$. Among the cases, the predominant occupation was farming (Table 1). Most of the transmission probably occurred outside of the home. Fishing was the only leisure activity associated with the focus. Contact with the imported case was common to a series of cases. Hospitalization occurred in $71 \%$ of the cases, but not in cases of serious and complicated malaria (Table 1).

Table 2 - Laboratory results for the first diagnosis, cure verification tests and occurrence of relapses of the autochthonous cases of malaria in the municipalities of Prata and Monte Alegre de Minas, Minas Gerais, 2005.

\begin{tabular}{lccccc}
\hline & & \multicolumn{3}{c}{ Cure verification tests } & \\
\cline { 3 - 5 } Case & First diagnosis & & \multicolumn{2}{c}{ Results } & Relapses \\
\cline { 3 - 5 } & (parasite species) & $\mathrm{n}^{0}$ & Positive & Parasite species & $\mathrm{n}^{0}$ \\
\hline 1 & $\mathrm{~V}$ & 5 & 0 & - & 0 \\
2 & $\mathrm{~F}+\mathrm{V}$ & 5 & 2 & $\mathrm{~V}, \mathrm{~V}$ & 0 \\
3 & $\mathrm{~V}$ & 9 & 1 & $\mathrm{~V}$ & 1 \\
4 & $\mathrm{~V}$ & 13 & 3 & $\mathrm{~V}, \mathrm{~V}, \mathrm{~V}$ & 1 \\
5 & $\mathrm{~F}$ & 7 & 3 & $\mathrm{~F}, \mathrm{Fg}, \mathrm{Fg}$ & - \\
6 & $\mathrm{~V}$ & 5 & 1 & $\mathrm{~V}$ & 0 \\
7 & $\mathrm{~V}$ & 2 & 0 & - & 0 \\
8 & $\mathrm{~V}$ & 3 & 0 & - & 0 \\
9 & $\mathrm{~F}$ & 7 & 1 & $\mathrm{~F}$ & - \\
10 & $\mathrm{~V}$ & 5 & 0 & - & 0 \\
11 & $\mathrm{~V}$ & 0 & 0 & - & 0 \\
12 & $\mathrm{~V}$ & 4 & 0 & - & 0 \\
13 & $\mathrm{~V}$ & 6 & 0 & - & 0 \\
14 & $\mathrm{~V}$ & 5 & 0 & - & 0 \\
\hline Total & - & $\mathbf{7 6}$ & $\mathbf{1 0}$ & - & $\mathbf{2}$ \\
\hline
\end{tabular}

F: Plasmodium falciparum, V: Plasmodium vivax, $\mathrm{F}+\mathrm{V}$ : Plasmodium falciparum and Plasmodium vivax, Fg: gametocytes of Plasmodium falciparum.

Laboratory investigation. During 2005, 170 blood samples were taken and examined, and the proportion found to be positive was $8 \%(14 / 170)$. Among the cure verification tests, $13 \%$ (10/76) were positive for Plasmodium spp. The two relapses that were notified occurred 59 days and 230 days respectively after the primary infection of these individuals (Table 2). In the laboratory diagnosis of the imported cases, the presence of Plasmodium falciparum was not detected, and the origin of the cases involving this parasite remained undetermined. One of these patients, however, reported having acquired mixed infection in the State of Pará, with incomplete therapy before arriving in the State of Minas Gerais.

Entomological investigation. Specimens of Anopheles darlingi (Root, 1926), Anopheles albitarsis (Lynch-Arribálzaga, 1878), Anopheles triannulatus (Neiva \& Pinto, 1922) and Anopheles parvus (Chagas, 1907) were captured in both municipalities. The entomological density was not determined, but it was empirically observed that there were specimens of the vector Anopheles darling $i$ inside and outside the home and specimens of Anopheles albitarsis, Anopheles triannulatus and Anopheles parvus only outside the home.

Means for eliminating the local transmission. The mean interval between the date of first symptoms in the autochthonous cases and the laboratory diagnosis was 7.4 days. The suspected cases were diagnosed within $24 \mathrm{~h}$. After the confirmation of the results, 
the patients were medicated immediately with specific antimalarial drugs. All of the cases recovered appropriately after the treatment. In March 2005, 126 homes were sprayed in the municipality of Prata and 104 in Monte Alegre de Minas. A second cycle of chemical treatment was performed in August 2005, in which 166 homes were sprayed in Monte Alegre de Minas and 98 in Prata. All of these homes were along the banks of the Tejuco river. Alpha-cypermethrin 200 SC (suspension concentrate) was used at a dilution of $0.005 \%$, in both cycles of spraying homes with insecticide.

\section{DISCUSSION}

The epidemiological findings from the investigation indicated that the autochthonous transmission route occurred by means of the bite of a locally infected Anopheles spp mosquito. As the individuals of the cases did not have any history of traveling to endemic areas or other possible exposures relating to malaria transmission of malaria, the presence of prospectors who were positive for Plasmodium vivax, along the Tejuco River, established a focus for the transmission. Imported cases of falciparum malaria were not encountered. However, one of the individuals of the imported cases reported that he had acquired mixed malaria in his region of origin (State of Pará), in December 2004 and that he had not undergone appropriate treatment. This suggests that a low parasitemia of gametocytes of Plasmodium falciparum may have persisted in this individual, at a level below the sensitivity of the thick blood smear test, for some weeks. This could explain the origin of the cases of malaria falciparum. On average, the ratio of gametocytes of Plasmodium falciparum to the asexual stages of the parasite is $1: 156$. The mean duration of circulation of these gametocytes is 6.4 days, although gametocytes with longevity of up to four weeks have been reported in the bloodstream ${ }^{415}$. The cases identified in July and October 2005 did not have, respectively, any temporal and temporal/spatial association with the first eleven cases. However, the frequent transitory presence of prospectors, truck drivers and woodworkers in this region, coming from malarial areas was probably the factor responsible for the appearance of these cases.

The finding of the species Anopheles darlingi demonstrates the potential for reintroduction of malaria in the area affected by the outbreak. The anthropophilic and endophilic habits of this species justified the spraying of insecticide inside homes in the area $^{3}$. However, it seems that transmission within the home did not have any relationship with the origin of the cases. Many of these individuals frequented the Tejuco river banks at the same time, which suggests that transmission outside of the home predominated. This suggested possible involvement of species of anophelines other than Anopheles darlingi that were found (Anopheles albitarsis, Anopheles trianullatus and Anopheles parvus), in spite of the lesser epidemiological importance of these vectors. The presence of Plasmodium falciparum and Plasmodium vivax in the transmission cycle suggests that Anopheles darlingi has significant involvement, given its susceptibility to these two parasites ${ }^{3}$.

The availability of means for early diagnosis and prompt treatment of the patients had fundamental importance in blocking the transmission cycle. In any antimalarial action, these objectives are of prime importance ${ }^{8}$. In areas outside of the Amazon region, timely detection and the elimination of outbreaks depends greatly on these actions ${ }^{14}$. The findings from this investigation underscore the importance of surveillance systems for malaria in nonendemic areas that are, however, vulnerable and receptive. They also highlight the role of reference laboratories, which are essential for rapid detection and diagnosis of autochthonous cases and for aiding in investigations of outbreaks ${ }^{1}$.

Because of intense migratory flows, travel to endemic areas and the high annual incidence of malaria around the world (300500 million cases), occurrences of autochthonous malaria in nonendemic areas are unlikely to be eradicated ${ }^{1}$. However, prompt reporting of patients with malaria to public health authorities makes it possible to institute effective actions aimed at preventing the reestablishment of malaria transmission ${ }^{1}$. Therefore, healthcare providers should consider malaria in the differential diagnosis of individuals with unexplained fever, particularly in those who report traveling to areas endemic for malaria, and should promptly report such cases to public health surveillance officials. Local and state health officials should recognize that cases of patients with positive diagnoses for malaria, without risk factors for the disease, suggest local infection until proven otherwise, and such cases should be investigated immediately ${ }^{1}$.

These cases shared common features with other outbreaks of malaria reported previously in the State of Minas Gerais, including: 1) presence of imported cases; 2) presence of competent malaria vectors; 3) proximity of the autochthonous cases to a imported case; and 4) environmental conditions favorable towards maturation of the parasite in the mosquito ${ }^{2}$.

The Triângulo Mineiro region presents several factors associated with malaria transmission. The presence of anthropophilic anophelines and collections of water, together with a long-distance highway that interconnects the Brazilian states that are endemic for malaria to the southeastern and southern regions, with frequent presence of individuals infected by Plasmodium spp, requires intense epidemiological surveillance, with the aim of avoiding reestablishment of malaria in this area.

\section{ACKNOWLEDGMENTS}

We thank the staff of the State Health Department of Minas Gerais and the Municipal Health Departments of Monte Alegre de Minas and Prata for assisting in the epidemiological investigations, and Iram Martins Costa for making the map for this article.

\section{REFERENCES}

1. Centers for Disease Control. Locally Acquired Mosquito-Transmitted Malaria: A Guide for Investigations in the United States. Morbidity and Mortality Weekly Report Recommendations and Reports 55: 1-9, 2006.

2. Chaves KM, Zumpano JF, Resende MC, Pimenta Junior FG, Rocha MOC. Malária em Minas Gerais, Brasil, no Período 1980-1992. Cadernos de Saúde Pública 11: 621-623, 1995. 
3. Consoli RAGB, Oliveira RL. Classificação e principais espécies de importância sanitária. In: Consoli RAGB, Oliveira RL (eds) Principais mosquitos de importância sanitária no Brasil, Fundação Oswaldo Cruz, Rio de Janeiro, p. 80-82, 1994.

4. Eichner M, Diebner H, Molineaux HL, Collins WE, Jeffery GM, Dietz K. Genesis, sequestration and survival of Plasmodium falciparum gametocytes: parameter estimates from fitting a model to malariatherapy data. Transactions of the Royal Society of Tropical Medicine and Hygiene 95: 497-501, 2001

5. Fundação Nacional de Saúde. Manual de terapêutica da malária. Ministério da Saúde, Brasília, 2001.

6. Gorham JR, Stojanovich CJ, Scott, HG. Clave ilustrada para los mosquitos anofelinos de Sudamerica Oriental. United States Department of Health, Education and Welfare, 1967.

7. Loiola CCP, Silva CJM, Tauil PL. Controle da malária no Brasil: 1965 a 2001. Revista Panamericana de Salud Pública 11: 235-244, 2002.

8. Najera JA. Malaria and the work of WHO. Bulletin of the World Health Organization 67: 229-243, 1989.
9. Secretaria Estadual de Saúde de Minas Gerais. Malária: noções básicas, terapêutica e controle. Secretaria Estadual de Saúde, Belo Horizonte, 2005.

10. Secretaria Estadual de Saúde de Minas Gerais. 0 perfil das doenças transmissíveis. In: Secretaria Estadual de Saúde de Minas Gerais, Análise da Situação de Saúde de Minas Gerais. Secretaria Estadual de Saúde, Belo Horizonte, p. 66-70, 2007.

11. Secretaria de Vigilância em Saúde. Guia de vigilância epidemiológica.

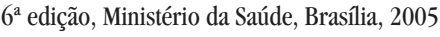

12. Secretaria de Vigilância em Saúde. Manual de diagnóstico laboratorial da malária. Ministério da Saúde, Brasília, 2005.

13. Secretaria de Vigilância em Saúde. Situação epidemiológica da malária no Brasil, 2007. Ministério da Saúde, Brasília, 2007.

14. Silveira AC, Rezende DF. Avaliação da estratégia global de controle integrado da malária no Brasil. Organização Pan-Americana de Saúde, Brasília, 2001.

15. Smalley ME, Sinden RE. Plasmodium falciparum gametocytes: their longevity and infectivity. Parasitology 74: 1-8, 1977. 